\title{
Moisés Maimónides, "médico de príncipes, príncipe de los médicos"
}

\author{
Jaime Cerda L.
}

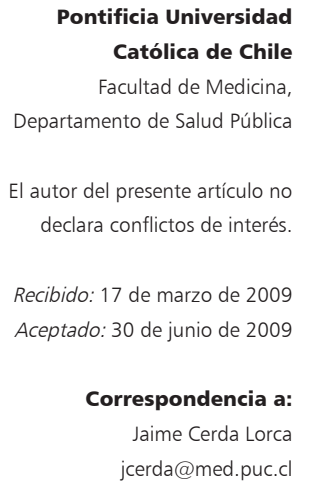

Correspondencia a: jcerda@med.puc.cl

\begin{abstract}
Moses Maimonides, "Physician of princes, prince of physicians"
Moses Maimonides (1135-1204) is considered the most prominent figure of Judaism during the Middle Ages. Born within the Sephardic Jewish community of Cordoba, his rich intellectual education (theological, philosophical and medical) together with a deep spirituality gave birth to the figure of a highly humanitarian, rational and dedicated physician. His medical legacy includes ten treatises, among them 'Medical Aphorisms of Moses', a set of 1,500 aphorisms organized in 25 chapters, each dealing with a different area of medicine. His theological works and the renowned 'Guide for the Perplexed' raised his figure as a theologist and modern philosopher, being the latest his most universal creation. His life and legacy are an invitation to raise the medical vocation and practice beyond a simple occupation.
\end{abstract}

Key words: Maimonides, Judaism, history.

Palabras clave: Maimónides, judaísmo, historia.

'El arte de Galeno cura solamente el cuerpo, pero el de Maimónides cura el cuerpo y el alma. Con su sabiduría es capaz de curar la enfermedad de la ignorancia.

Y si la luna apelara a su arte, de sus manchas la libraría,

de todos sus defectos crónicos habría de despojarla: hasta la curaría de su palidez en la época de conjunción'.

Ibn Sina Almuk (poeta).

\section{Introducción}

M oisés Maimónides (1135-1204) es considerado unánimemente la figura más prominente del judaísmo durante el período medieval (Figura 1). Su riquísima formación intelectual (teológica, filosófica y médica) unida a una profunda espiritualidad dio forma a la figura de un médico altamente humanitario, racional y abnegadamente dedicado a su trabajo. Transcurridos ocho siglos de su muerte, el presente artículo resume los principales aspectos biográficos de este médico ejemplar, cuya legado incluye importantes aportes en el área de la Infectología, muchos de ellos vigentes hoy en día.

\section{Los judíos en la Península Ibérica}

La presencia de judíos en la Península Ibérica (en hebreo, Sefarad) posiblemente se remonte al siglo I de nuestra era, a consecuencia de su segunda diáspora. La primera diáspora había ocurrido el año 586 a.C. tras la conquista del Reino de Judá por Nabucodonosor II, rey de los babilonios. Seis siglos después, en el año 70 d.C., se produce la segunda diáspora judía, esta vez a manos del general y futuro emperador romano Tito, quien aplastó una rebelión judía y expulsó a los habitantes del territorio de Israel. Un mayor número de judíos fue expulsado después de ser aplastado el levantamiento de Bar Kojba, en el año 135 d.C. El pueblo judío se dispersó por el Imperio Romano, siendo la Hispania romana uno de sus destinos más lejanos. Establecidos en la Península Ibérica, los judíos españoles, portugueses y sus descendientes (conocidos como sefardíes) vivieron hasta el siglo $\mathrm{V}$ bajo el dominio de Roma. Tras la caída del imperio, los reyes visigodos gobernaron la región, protagonizando intensas persecuciones contra los judíos residentes. Con gran regocijo vieron los sefardíes la llegada de los ejércitos árabes del norte de África liderados por el general bereber Táriq ibn Ziyad, quien conquistó a comienzos del siglo VIII parte de la península, estableciendo un dominio que se extendería por casi ochocientos años. Dicho dominio finalizaría en 1492 con la toma de Granada por los Reyes Católicos de manos del rey nazarí Boabdil, concluyendo así el período histórico conocido como Reconquista Española ${ }^{1}$.

Entre el siglo VIII y la mitad del siglo XII, la libertad religiosa imperante en Al-Andalus (denominación árabe de la Península Ibérica) permitió el florecimiento de la comunidad judía sefardí, la más grande y desarrollada de toda la diáspora judía. La convivencia armónica de árabes, judíos y cristianos transformó al sur de España 


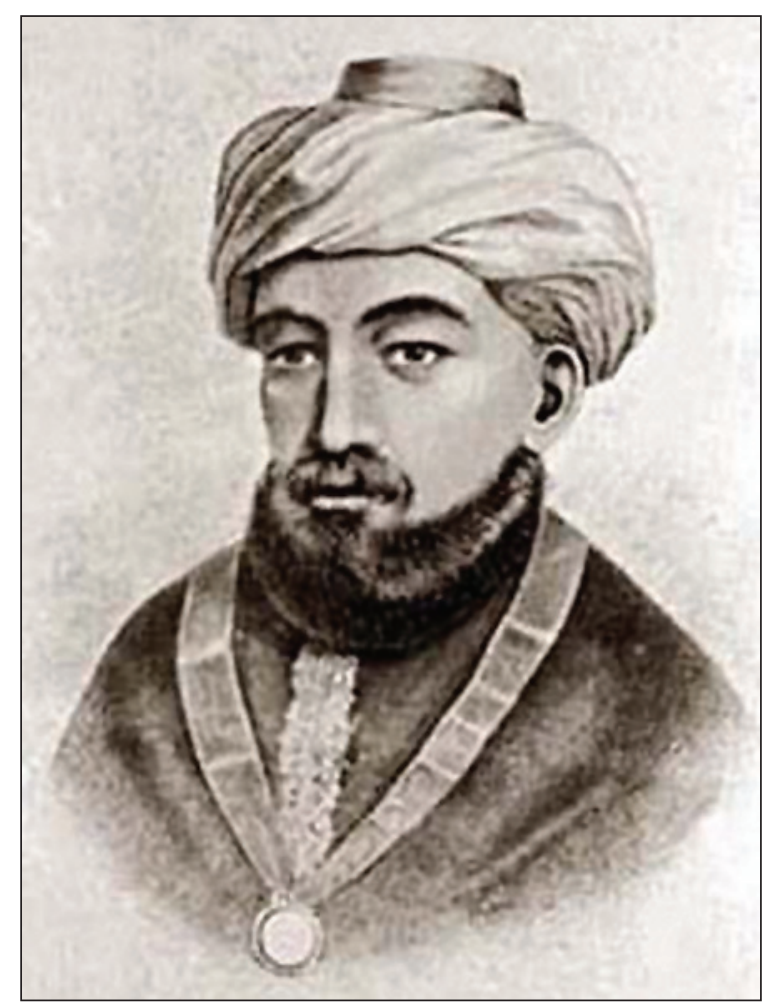

Figura 1. Retrato de Moisés Maimónides (siglo XIX). * Obra considerada de dominio público por Wikipedia.

en el mayor centro cultural del mundo durante la Edad Media, cuna de grandes intelectuales, cuyo legado perdura hasta nuestros días ${ }^{2}$.

\section{El médico cordobés}

En la ciudad de Córdoba, capital de Al-Andalus, el 30 de marzo de 1135 nació Maimónides (en griego, 'hijo de Maimón'). Filósofo, teólogo y médico, RaMBaM (acrónimo de sus iniciales en hebreo, Rabí Moshé ben Maimón) es considerado la figura más prominente del judaísmo durante el período medieval. Hijo del Rabí Maimón, un ilustre magistrado cordobés cuyo linaje descendía de la casa del mismísimo Rey David, Maimónides recibió una riquísima formación intelectual iniciada por su padre. Para aquel entonces, la ciudad de Córdoba era el corazón de la vida intelectual y artística española, transcurriendo su infancia en el mejor ambiente docente imaginable. Por desgracia, siglos de convivencia pacífica entre árabes, judíos y cristianos experimentó un abrupto final en 1148 tras la conquista de Al-Andalus por los fundamentalistas almohades, quienes forzaron a judíos y cristianos a elegir entre la conversión al Islam, el destierro o la muerte ${ }^{1-3}$.

Con tan sólo 13 años, Maimónides y su familia deambularon por diferentes lugares del sur de España y norte de África durante una década, estableciéndose en Fez, Marruecos, en 1158. En esta ciudad Maimónides completó su formación talmúdica e inició sus estudios médicos, recibiendo las enseñanzas impartidas por grandes médicos árabes. Poco se conoce sobre su formación médica, sin embargo, es presumible que haya sido un ávido lector, pues su obra refleja un profundo conocimiento de escritos de médicos griegos e islámicos, destacando Hipócrates y Galeno entre los primeros y Al-Razí (Rhazes) e IbnZuhr (Avenzoar) entre los segundos. La intolerancia y sectarismo religioso imperante en Fez obligaron a la familia Maimón a iniciar nuevo exilio en 1165, primero a Palestina y luego a Fostat (antiguo El Cairo, Egipto), lugar donde estableció su residencia definitiva ${ }^{4,5}$.

La tragedia nuevamente azotó su vida al fallecer su padre y su hermano David en 1166, debiendo asumir el cuidado de su cuñada y sobrina. Al año siguiente, Maimónides presentó una enfermedad que lo postró e impidió trabajar por cerca de un año. Una vez recuperado abrazó la práctica de la medicina por completo, principalmente como una forma de sustento de su familia. Su sabiduría, habilidad y empatía hicieron que su reputación rápidamente se extendiera. En 1174 el visir Al-Fadil (Alfadal), regente de Egipto y sultán subrogante en ausencia de Saladino el Grande (quien combatía a los Caballeros Cruzados en Tierra Santa), lo nombra médico de la corte, a la edad de 39 años. Por su parte, el rey inglés Ricardo Corazón de León (quien participó activamente en la Tercera Cruzada) le invita a unírsele como su médico personal, ofrecimiento que Maimónides rechaza ${ }^{1,5}$.

\section{El legado de Maimónides}

La abundante obra médica de Maimónides, escrita en lengua árabe, fue realizada en la última etapa de su vida. Su producción literaria consta de diez tratados ${ }^{3}$. El primero se titula 'Extractos de Galeno' y corresponde a una síntesis de las enseñanzas más importantes del médico griego (cerca de 100 libros), cuyo objetivo fue el facilitar su estudio y comprensión por los estudiantes de medicina. El segundo se titula 'Comentario sobre los aforismos de Hipócrates', obra en que comenta y ocasionalmente critica a Hipócrates y Galeno cuando éstos difieren de sus observaciones (por ejemplo, critica la afirmación de Hipócrates 'un varón nace del ovario derecho y una mujer del izquierdo', señalando que 'un hombre debería ser un profeta o un genio para saber esto'). Su tercera obra y más voluminosa se titula 'Aforismos médicos de Moisés'. Esta incluye 1.500 aforismos organizados en 25 capítulos, cada uno versando sobre un área diferente de la medicina, tales como anatomía, fisiología, patología, sintomatología y diagnóstico, etiología de enfermedades y terapéutica, fiebres, flebotomías, laxantes y eméticos, cirugía, ginecología, higiene, dietética, farmacología y curiosidades médicas. De gran vigencia es su descripción del cuadro 
clínico de la neumonía, vigente hasta nuestros días:

'Los síntomas básicos que ocurren en la neumonía y que nunca están ausentes son los siguientes: fiebre aguda, dolor tipo puntada de costado, respiraciones cortas y rápidas, pulsus serratus y tos, mayoritariamente asociada a expectoración'3.

De igual forma, ofrece una lúcida descripción del cuadro clínico de la hepatitis:

'Los signos de la inflamación hepática son ocho: fiebre alta, sed, anorexia completa, una lengua inicialmente roja que luego se torna negra; vómitos biliosos, inicialmente del color de la yema del huevo y posteriormente verde oscuro; dolor en el costado derecho que asciende hasta la clavicula (...) ocasionalmente puede presentarse tos leve y una sensación de pesadez que inicialmente se siente en el costado derecho y luego se expande ampliamente, 3 .

Completan su obra médica una serie de tratados, titulados 'Tratado sobre las hemorroides', 'Tratado sobre el coito', 'Tratado sobre el asma', 'Tratado sobre los venenos y sus antídotos', 'Tratado sobre el régimen de la salud' y 'Tratado sobre las causas de los síntomas' y la obra 'Comentario sobre los nombres de las drogas', glosario de 450 párrafos cortos que incluye nombres de drogas en árabe, griego, sirio, persa, bereber y español $1^{1,3}$.

En el área de la Infectología, Maimónides describió numerosas enfermedades, signos y síntomas, destacando abscesos, blefaritis, carbunco, conjuntivitis, disentería, gangrena, hepatitis, lepra, neumonía y sepsis, entre otras. En las postrimerías del reinado de Saladino, el cólera

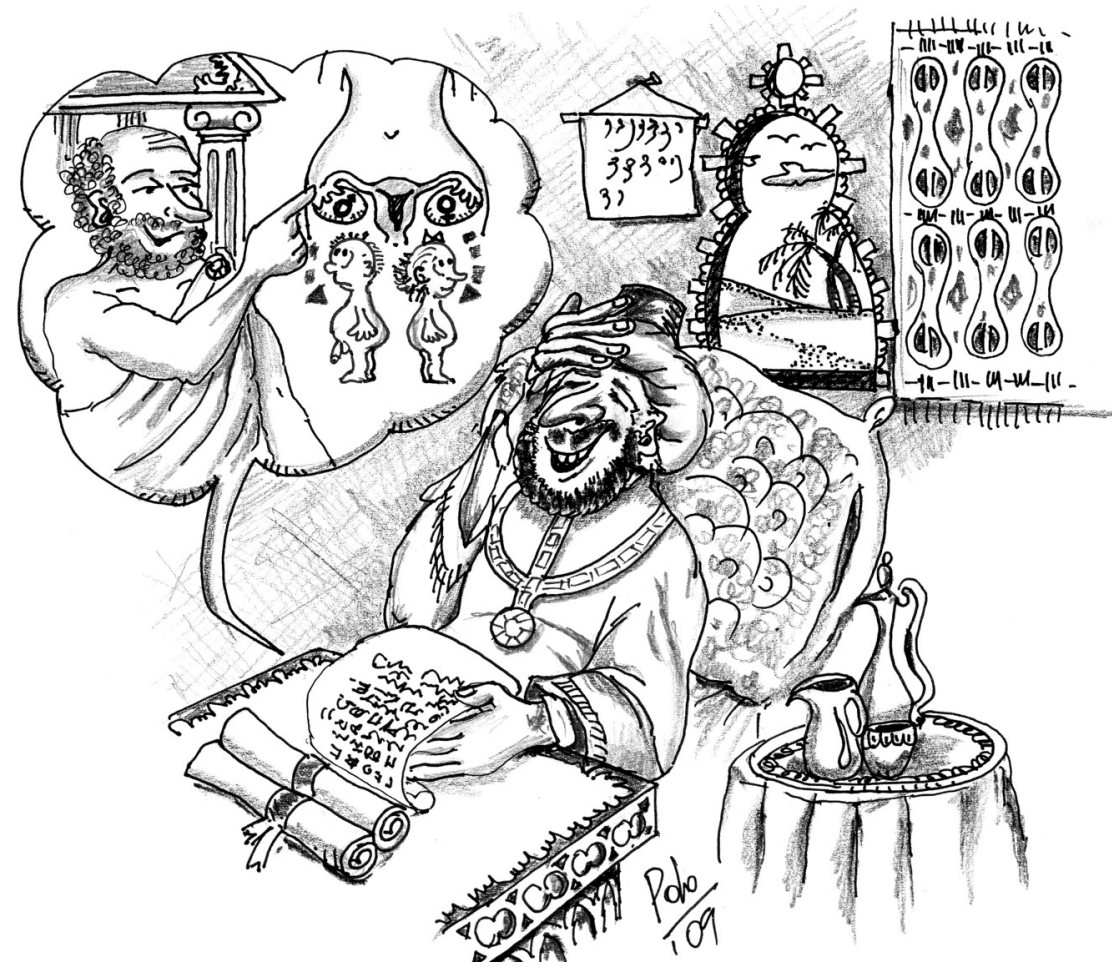

morbo se declaró en El Cairo, procedente de la India, afectando a un gran número de personas (el número de hospitalizados habría excedido los 1.500). Para combatir los vómitos y diarrea que provoca esta enfermedad, Maimónides dispuso la preparación de una bebida compuesta de goma de Arabia, arroz y corteza de pan, posiblemente una de las primeras soluciones rehidratantes conocidas. Sus nociones de higiene tienen plena vigencia en nuestros días, proscribiendo la ingesta de carnes descompuestas y alimentos que desprenden olor, recomendando la higiene y el aseo ${ }^{2}$.

Si el legado médico de Maimónides excede con creces el necesario para asegurar un lugar en la historia, sus contribuciones teológicas y filosóficas habrían tenido igual consecuencia. Maimónides es considerado uno de los pensadores más influyentes en teología y filosofía occidental. Tres son sus obras más importantes, siendo la primera de ellas 'Comentario a la Mishná' (1168), conocida también como 'Libro Iluminador'. Diez años después termina 'Mishné Torá' (1178), su obra maestra teológica, consistente en una síntesis y organización sistemática de la ley bíblica y rabínica, también conocida como 'Código de Maimónides'. Finalmente, en 1190 acaba su obra maestra filosófica, titulada 'Guía de Perplejos'. Mientras las dos primeras obras lo consagraron como un maestro del judaísmo, esta última obra alzó su figura como filósofo, siendo considerada la más universal de sus creaciones. Profundo conocedor de la obra de Aristóteles, Maimónides marca la expresión cumbre del racionalismo judío medieval; tuvo confianza plena en la razón, no como recurso infalible de análisis, pero sí como el único instrumento del cual disponemos para nuestra insaciable búsqueda de la verdad de Dios y de las cosas. Sus ideas ejercieron una influencia considerable sobre algunos teólogos de la Iglesia Católica, por ejemplo, Santo Tomás de Aquino ${ }^{1,4}$.

La descripción de los aportes de Maimónides a la medicina, teología y filosofía abarcarían decenas de páginas, especialmente considerando las complejas circunstancias biográficas que caracterizaron su vida. Restringiéndose a su práctica y legado médico, es posible afirmar que encarnó las virtudes a alcanzar por todo aquel que practica la medicina: humanitarismo, intelectualidad y dedicación. Maimónides falleció el día 13 de diciembre de 1204 en El Cairo, cuando aún no había cumplido los 70 años. Su muerte fue sentida por judíos, cristianos y musulmanes, quienes guardaron un riguroso luto en su memoria. Cumpliendo el deseo de su padre, su hijo Abraham trasladó su cadáver a Tiberíades, donde fue sepultado. En su lápida reza la siguiente inscripción: 'De Moisés (el bíblico) a Moisés (Maimónides), nadie hubo semejante a Moisés', pues tal fue su transcendencia para el mundo judío que fue llamado 'el segundo Moisés'.

En Córdoba, su ciudad natal, una estatua de bronce 


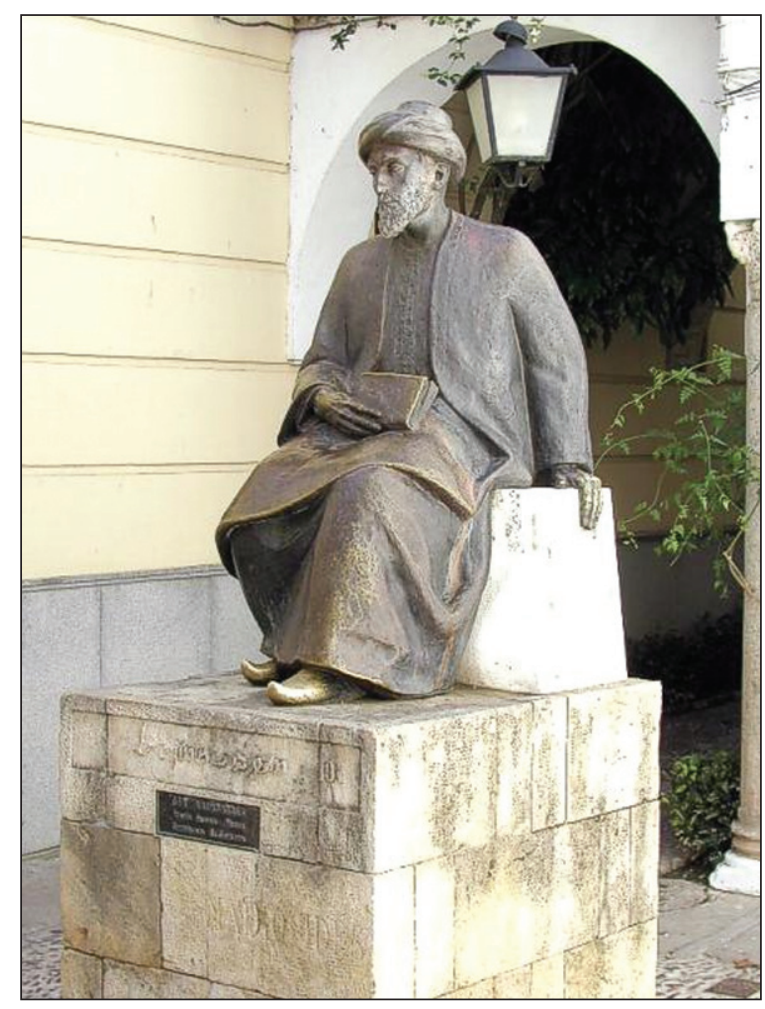

Figura 2. Estatua de Moisés Maimónides (Plaza de Tiberíades, Córdoba). * Obra considerada de dominio público por Wikipedia.

ubicada en el barrio judío recuerda a su hijo más ilustre e universal (Figura 2). Fred Rosner, uno de sus principales biógrafos, sintetiza magistralmente su vida y legado:

'Su habilidad literaria fue increíble y su conocimiento enciclopédico. Él fue un maestro en prácticamente todos los campos de la teología, matemáticas, filosofía, astronomía, ética y, por supuesto, medicina. Como médico, él trató las enfermedades basándose en el método científico, dejando a un lado las adivinanzas, supersticiones y reglas preconcebidas. Su actitud hacia la práctica de la medicina se fundamentó en sus profundas creencias religiosas, las cuales transformaron la preservación de la salud y de la vida en un mandato divino. Su inspiración perdura a través del tiempo y su sitial como uno de los gigantes de la medicina es indeleble. Él fue médico de sultanes y príncipes, y tal como señalara Sir William Osler, Maimónides fue también 'príncipe de los médicos'3.
Sin lugar a dudas, la profunda intelectualidad y especialmente la espiritualidad de Maimónides fueron dos elementos cuya conjunción le elevaron a la categoría de médico excepcional y ejemplar. Trascurridos ocho siglos de su muerte, la invitación de Maimónides a elevar la vocación y profesión médica más allá de un simple oficio sigue plenamente vigente.

Agradecimientos. El autor agradece a Cristián García Bruce por su revisión crítica y aportes al presente manuscrito.

\section{Resumen}

Moisés Maimónides (1135-1204) es considerado unánimemente la figura más prominente del judaísmo durante el período medieval. Nacido en el seno de la comunidad judía sefardí cordobesa, su riquísima formación intelectual (teológica, filosófica y médica) unida a una profunda espiritualidad dio origen a la figura de un médico altamente humanitario, racional y abnegadamente dedicado a su trabajo. Su legado médico consta de diez tratados, entre los cuales destaca la obra 'Aforismos Médicos de Moisés', un conjunto de 1.500 aforismos organizados en 25 capítulos, cada uno versando sobre un área diferente de la medicina. Sus obras de carácter teológico y la célebre 'Guía de Perplejos' alzaron su figura como teólogo y filósofo moderno, siendo esta última considerada la más universal de sus creaciones. Su vida y obra son una invitación a elevar la vocación y profesión médica más allá de un simple oficio.

\section{Referencias}

1.- Simon S. Moses Maimonides. Medieval physician and scholar. Arch Intern Med 1999; 159: 1841-5.

2.- Casal M T, Casal M. Ocho siglos de la muerte de un gran médico: ‘Maimónides El Español' Enferm Infecc Microbiol Clin 2004; 22: 660-2.

3.- Rosner F. The life of Moses Maimonides, a prominent medieval physician. Einstein Quart J Biol Med 2002; 19: 125-8.

4.- Rosner F. Moses Maimonides and the diseases of the chest. Chest 1971; 60: 68-72.

5.- Goic A. Capítulo 3: Haz que no vea más que al hombre en aquel que sufre. Goic A. Grandes Médicos humanistas. Primera Edición, Santiago, Editorial Universitaria 2004; 4969. 